\title{
CULTURA E RELAÇÕES DE RECIPROCIDADE: A LITERATURA DE CORDEL EM DIFERENTES CONTEXTOS
}

\author{
Gabriela Kvacek Betella* \\ Bárbara Laís Falcão da Silva Cação**
}

\begin{abstract}
Resumo: O presente trabalho comenta brevemente as características do cordel brasileiro e de que forma seus elementos se combinam com os elementos da cultura popular. Algumas considerações sobre cultura atuam de forma pertinente na discussão do lugar ocupado pela cultura popular no Brasil não somente junto ao público comum, mas também em face das problematizações acadêmicas. Há ainda rápida exposição a respeito das diferenças entre a literatura de cordel pioneira e contemporânea, o que nos ajuda no entendimento do processo de declínio atravessado por essa produção, por volta dos anos 1950/60 e de sua revitalização, já que segue sendo escrita e lida em diferentes partes do país. Ao contrário do que ocorreu em outros países, os folhetos brasileiros resistiram e resistem ao ostracismo.
\end{abstract}

Palavras-chave: Cordel. Cultura Popular. Cultura. Declínio. Revitalização.

Abstract: This paper briefly comments about the characteristics of the Brazilian string literature and how its elements combine with the elements of popular culture. Some considerations about culture act in a relevant way in the discussion about popular culture in Brazil, not only regarding common public, but also in the face of academic discussions. There is also a brief discussion on the differences between pioneer and contemporary string literature, which helps us understand the process of decline around the $50 / 60$ s and its revival, as it is still written and read in different places of the country. Different from what happened in other countries, the Brazilian string literature has faced no ostracism.

Keywords: String literature. Popular culture. Culture. Decline. Revival.

\section{Sobre cultura e relações de reciprocidade}

Ao pensarmos em literatura de cordel é preciso levar em consideração o fato de que, apesar de este segmento repetir alguns esquemas e contar com estruturas que se mantêm quase inalteradas ao longo de diferentes períodos, uma coisa é certa: não há como falar em cordel atribuindo a esta produção o rótulo produção regional. Temos o entendimento da pluralidade desta forma de produção que resulta da combinação de diversos fatores, e assim, é importante comentar as noções de cultura e suas relações, para que seja possível compreender melhor o universo da literatura de cordel.

Para isso, é preciso pontuar que sempre houve uma distinção, sobretudo em âmbito acadêmico, entre popular e erudito, justificada, em especial, por uma divisão de classes, como se o popular pertencesse aos mais pobres, aos iletrados e a cultura erudita, por sua vez, às pessoas bem-postas socialmente.

Desta forma, devemos levar em consideração que, apesar da divisão em categorias, não existe uma linha fixa separando cultura popular e erudita. Isso não ocorre hoje e também não ocorreu em outros momentos da história, levando-nos a crer na possível existência de uma "circularidade" dos níveis de cultura, tendo em mente que por muito tempo se acreditou que somente as classes dominantes poderiam compor uma arte original e genuína, gerando um problema na compreensão desse processo por parte dos estudos históricos, como observa Carlo Ginzburg em $O$ queijo e os vermes:

\footnotetext{
* Doutora docente da UNESP - FCL/Assis. Endereço eletrônico: gabrielakvacek@uol.com.br

${ }^{*}$ Mestra em Literatura e Vida Social pela UNESP - FCL/Assis. Endereço eletrônico: barbarafalcaoc@hotmail.com
} 
Os historiadores só se aproximaram muito recentemente - e com certa desconfiança - desses tipos de problema. Isso se deve em parte, sem dúvida nenhuma, à persistência de uma concepção aristocrática de cultura. Com muita frequência ideias ou crenças originais são consideradas, por definição, produtos das classes superiores, e sua difusão entre as classes subalternas um fato mecânico de escasso ou nenhum interesse; como se não bastasse, enfatiza-se presunçosamente a "deterioração", a "deformação", que tais ideias ou crenças sofreram durante o processo de transmissão. (GINZBURG, 2006, p. 12)

Quando Ginzburg fala em "circularidade" e reciprocidade no âmbito da cultura popular, há uma nítida problematização das concepções presentes nos trabalhos de alguns teóricos como Robert Mandrou, que num primeiro momento afirmou ser a literatura de cordel uma literatura de evasão, e que suas temáticas eram todas fatalistas e incapazes de suscitar em seus leitores uma consciência social e a compreensão da própria condição. (apud GINZBURG, 2006, p. 13).

$\mathrm{O}$ autor comenta também os estudos de Geneviève Bollème que, segundo ele, elaborou uma concepção bastante ingênua sobre a literatura de cordel, tendo com isso construído uma linha de pensamento muito estereotipada em torno da cultura popular, como se suas produções se baseassem somente em valores religiosos e provincianos.

Mas é o estudo realizado por Mikhail Bakhtin sobre Rabelais que oferece um contraponto aos trabalhos anteriormente citados, mormente pelo fato de estabelecer relações de reciprocidade entre cultura popular e erudita. Ginzburg assevera que, também para Bakhtin, a compreensão da relação que se estabelece entre cultura popular e erudita passa pela ideia de "circularidade":

É bem mais frutífera a hipótese formulada por Bakhtin de uma influência recíproca entre a cultura das classes subalternas e a cultura dominante. Mas precisar os modos e os tempos dessa influência significa enfrentar o problema posto pela documentação, que no caso da cultura popular, é, como já dissemos, quase sempre indireta. Até que ponto os eventuais elementos da cultura hegemônica, encontráveis na cultura popular, são frutos de uma aculturação mais ou menos deliberada ou de uma convergência mais ou menos espontânea e não, ao contrário, de uma inconsciente deformação da fonte, obviamente tendendo a conduzir o desconhecido ao conhecido, ao familiar? (GINZBURG, 2006, p. 18)

Com base nas considerações acima, chegamos à conclusão de que as manifestações artísticas populares representam e representaram por longo período, a continuação das histórias contadas de geração em geração por um viés fortemente oral.

A memória aparece como um aspecto importante de conservação desta prática de registro. Mais ainda quando se trata da poesia popular ou das narrativas em versos, como as produzidas no âmbito da literatura de cordel, que utiliza o esquema de rimas para auxiliar na memorização das narrativas pelo público, e também de figuras como o cantador, transmissor da tradição por meio da voz e do conhecimento acumulado.

Outro elemento a ser comentado quando discutimos os conceitos de memória e tradição diz respeito aos aspectos herdados da tradição medieval. Esses aspectos estão presentes até mesmo na escolha da praça pública como espaço de circulação dos folhetos (essencialmente na fase inicial), bem como na pessoa do próprio cordelista, por 
vezes cantador (quando não "poeta de gabinete") ou do cantador propriamente dito, como nos mostra Francisco C. A. Marques ao observar as relações entre a sátira no contexto nordestino e a contribuição da visão carnavalizada do mundo na elaboração desta literatura:

Cabe salientar que estas tradições trouxeram na memória aspectos da cultura cômica da praça pública medieval, os quais se prestaram muito bem à representação da realidade do sertão. A visão carnavalizada do mundo, amalgamada às novas condições climáticas, econômicas e socioculturais, tornar-se-ia mais um elemento na formação do espírito satírico como mecanismo social de resistência, espécie de lentes com que o nordestino passaria a ver e interpretar o mundo e seus acontecimentos. Basta pensarmos nas manifestações culturais do Judas, o pau de sebo, o circo, o Carnaval, as quermesses no adro da igreja, as feiras dominicais realizadas na praça do mercado municipal, e sobretudo, a literatura de cordel. (MARQUES, 2014, p. 34).

Entendemos que a memória - individual e coletiva - possui um papel muito importante na difusão da literatura de cordel, bem como de outras formas de expressão popular, tendo em mente que tal fenômeno ocorreu não só no Brasil, mas também em países europeus que produziam os "livretos" populares com diferentes denominações, como littérature de colportage, na França, pliegos sueltos, na Espanha, e letteratura muricciolaia, na Itália. As diferentes nomenclaturas e a "universalidade" dos temas tratados nessas produções populares são lembradas por Ivan Cavalcante Proença:

Esta reconstituição, o seu tanto rápida, de algumas manifestações em países latino-americanos, da literatura de cordel, nos permite mostrar que a inspiração popular que a criou, se não é universal, é muito espalhada; há na França através da littérature de colportage; há na Espanha através dos pliegos sueltos; há em Portugal, com as "folhas soltas" ou literatura de cordel[...] (PROENÇA, 1982, p. 30).

Além da denominação "folhas soltas", Proença observa que a denominação "literatura de cordel" apareceu primeiramente em Portugal, e segue sendo utilizada no Brasil ainda hoje, apesar de outros nomes também aparecerem no cenário em diferentes contextos. Mas o que nos interessa mais diretamente, é o fato de que o nome "cordel" aparece no Brasil mais como uma apropriação que por algo que se justifique de fato, como podemos apreender das informações de Luyten:

Em Portugal e Galícia, porém, tem-se notícias de publicações populares até hoje - quase todas em prosa. É da península ibérica que vem o nome literatura de cordel, pois os livretos eram expostos em lugares públicos pendurados sobre barbantes. No Brasil, o costume sempre foi o de se expor os folhetos no chão, sobre as folhas de jornal ou dentro de uma mala aberta. Isso permitia ao vendedor poder evadirse rapidamente quando aparecia algum guarda ou fiscal. Mesmo assim os estudiosos persistiram no nome literatura de cordel e, hoje, dificilmente alguém a chama por outro nome. (LUYTEN, 1987, p. 32$33)$.

A aproximação do nosso cordel com a chamada literatura de cordel praticada em Portugal não se justifica somente pelo estabelecimento de uma dependência direta 
entre um país colonizado e seu colonizador, mas também por uma tentativa de se apropriar de uma cultura eurocêntrica, ainda que a literatura de cordel permita que tenhamos acesso aos meandros da existência de aspectos intrinsecamente ligados às culturas populares. Além disso, temos ainda uma preocupação enorme no que se refere às pesquisas realizadas, com o estudo das fontes, o que demonstra que, por vezes, o pesquisador brasileiro esteja mais preocupado em comprovar a relação de dependência com as matrizes ibéricas que tomar como objeto nossos cordéis propriamente ditos.

Silviano Santiago (2009, p. 9-26) chama a atenção para os métodos de pesquisa adotados pelos estudiosos de literatura embasados em fontes e influências assentadas na dicotomia "reacionário" / "conservador". A postura dessa ordem de pesquisadores explica o olhar superior que muitas vezes nos espaços acadêmicos lançamos às produções populares, haja vista que, muitas vezes, nos posicionamos apenas do ponto de vista da cultura erudita, ignorando a ideia bakhtiniana de circularidade entre as culturas "alta" e "baixa" anteriormente mencionada por Ginzburg (2006).

As produções artístico-populares e consequentemente transmitidas pelo concurso da voz enfrentaram desde sempre uma relativa rejeição por parte de uma camada dita mais intelectualizada, principalmente no Brasil, tendo sempre ficado à margem das produções que estudamos na academia. Este fenômeno ocorreu e ainda ocorre mais timidamente, ainda que a literatura de cordel, por exemplo, tenha encontrado na contemporaneidade leitores de diversos países e pesquisadores estrangeiros que têm dado uma contribuição importante para a compreensão desse tipo particular de literatura.

O cordel, bem como outras manifestações artísticas ligadas à oralidade, por muito tempo se situou à margem, talvez não por preconceito, mas pela sua ligação com a praça pública e pela sua difusão em espaços populares e não consagrados pela cultura das elites, o que acabou deixando-o quase invisível aos olhos dos intelectuais. Mas essas considerações classificatórias não são o aspecto mais importante para as discussões apresentadas neste trabalho, e sim, a função e a influência que o cordel exerce sobre seu público desde os primeiros folhetos manuscritos e cantados por poetas-cantadores até as versões impressas na atualidade.

Pensando na necessidade de o ser humano se expressar artisticamente e de identificar-se por meio da arte, Antonio Candido (1988), apesar de não tratar especificamente do cordel, esboça algumas considerações acerca dos direitos humanos para pensarmos a importância da literatura na formação do homem. Para esclarecer de que forma se dá essa necessidade dos homens em relação à literatura, Antonio Candido observa que neste grande grupo, devem ser consideradas todas as "criações de toque poético, ficcional ou dramático", tornando possível uma reflexão acerca do papel social exercido pela literatura:

Vista deste modo a literatura aparece claramente como manifestação universal de todos homens em todos os tempos. Não há povo e não há homem que possa viver sem ela, isto é, sem a possibilidade de entrar em contato com alguma espécie de fabulação. Assim como todos sonham todas as noites, ninguém é capaz de passar as vinte e quatro horas do dia sem alguns momentos de entrega ao universo fabulado. $\mathrm{O}$ sonho assegura durante $\mathrm{o}$ sono a presença indispensável deste universo, independente da nossa vontade. E durante a vigília, a criação ficcional ou poética, que é a mola da literatura em todos os seus níveis e modalidades, está presente em cada um de nós, analfabeto ou erudito, como anedota, causo, história em quadrinhos, noticiário policial, canção popular, moda de viola, samba carnavalesco. Ela se 
manifesta desde o devaneio amoroso ou econômico no ônibus até a atenção fixada na novela de televisão ou leitura seguida de um romance. (CANDIDO, 1988, p. 174-175).

Essa informação não aparece aqui desrespeitando seu contexto com objetivismo leviano que pressupõe que não devamos fazer juízo de valor dos textos literários, até porque isso contrariaria e muito o papel do próprio crítico literário, em óbvia dissonância com as intenções do próprio Candido.

O juízo de valor dos textos não só existe, como também se verifica em cada processo analítico, e nos auxilia quando bem construído porque a forma só vem reforçar as intenções de um escritor na escolha de cada temática. Isso também ocorre na literatura popular: forma e conteúdo se unem para caracterizar folhetos e personagens.

Antonio Candido enfatiza que não podemos ignorar a indiferença existente relativa às formas de criação poética em diferentes níveis e contextos que continuam a contribuir para a fabulação de cada indivíduo, acreditando ser esta tão necessária que o nosso próprio corpo a produz por meio dos sonhos, e que nós a produzimos também por meio da elaboração ou da recepção dos textos literários.

A importância desta fabulação não está numa simples explicação psicanalítica segundo a qual precisamos de momentos de "fuga" para conviver com as realidades duras, seja por meio da literatura ou por meio dos devaneios mais despretensiosos, mas consiste também, segundo assinala Candido, no próprio processo "humanizador" pelo qual todos necessitamos passar, por isso faz as seguintes considerações sobre a literatura:

[...] frui-la é um direito das pessoas de qualquer sociedade, desde o índio que canta as suas proezas de caça ou evoca dançando a lua cheia, até o mais requintado erudito que procura captar com sábias redes os sentidos flutuantes de um poema hermético. Em todos esses casos ocorre humanização e enriquecimento, da personalidade e do grupo, por meio do conhecimento oriundo da expressão submetida a uma ordem redentora da confusão. (CANDIDO, 1988, p. 180).

No que se refere ao direito à literatura, compreendemos então, que ele não só é válido, mas se manifesta independentemente do aval de determinados meios que procuram definir ou redefinir o que é literariamente bom e o que não é, e mais problemático, o que deve ou não ser lido por conjuntos de pessoas que formam grupos heterogêneos e que se dividem em contextos em sempre homogêneos. Assim, entendemos que as produções culturais não podem ser rotuladas e nem segregadas, até porque não há texto do mais alto requinte que não tenha sido, em algum momento, influenciado por manifestações populares e, portanto, o direito à literatura contempla a todos:

Portanto, a luta pelos direitos humanos abrange a luta por um estado de coisas que todos possam ter acesso aos diferentes níveis de cultura. A distinção entre cultura popular e cultura erudita não deve servir para justificar e manter uma separação iníqua, como se do ponto de vista cultural a sociedade fosse dividida em esferas incomunicáveis, dando lugar a dois tipos incomunicáveis de fruidores. Uma sociedade justa pressupõe o respeito dos direitos humanos, e a fruição da arte e da literatura em todas as modalidades e em todos os níveis e é um direito inalienável. (CANDIDO, 1988, p. 191). 
As considerações anteriores foram feitas para situar o cordel não no cenário de seu público mais costumeiro e sim nos espaços acadêmicos, ressaltando não só a importância da dedicação aos estudos culturais, mas também quantas lacunas ainda existem na compreensão do processo de produção e difusão da literatura de cordel. Isso somado ao fato de que é bastante curioso que essa forma de produção tenha resistido até hoje no Brasil - mais de cem anos da publicação dos primeiros folhetos -, suscitando interesse de leitores e pesquisadores, não só no Nordeste, mas também no Sul e Sudeste.

E para a compreensão deste fenômeno nada mais acertado do que conhecer um pouco mais pormenorizadamente a literatura de cordel, o que continua sendo cultivado pelos poetas populares e o mais importante: em que o cordel atual se diferencia daquele produzido na Primeira República, para assim, explicar seu processo de revitalização.

\section{Cordel de ontem e cordel de hoje}

Apesar do hibridismo e das modificações sofridas pelo cordel brasileiro, uma coisa é certa, a oralidade continua sendo a espinha dorsal dessa produção. A oralidade não se observa somente para que haja marcação de estilo, mas também é verificada no ritmo, na musicalidade e na necessidade da leitura em voz alta.

Sobre a presença da oralidade, independentemente da época em que os folhetos foram produzidos, ainda é válida a consideração de Paul Zumthor (1980), presente no artigo A escrita e a voz (de uma literatura popular brasileira), segundo a qual a literatura de cordel, apesar de escrita, continua recorrendo a "procedimentos de composição oral" e, consequentemente, atraindo o público por meio da audição e da leitura.

O autor explicita que o folheto de cordel, pelo simples fato de chegar às nossas mãos no formato escrito, já pressupõe uma necessidade de ser lido, embora os índices de oralidade nele presentes quase nos obriguem a lê-los em voz alta, retomando assim, mesmo na contemporaneidade, a figura do cantador, através do qual o indivíduo pouco ou não escolarizado poderia ter acesso aos versos. Desta forma, o "convite à recitação pública" permanece atual e vivo na literatura de cordel e é observado por Zumthor nos seguintes termos:

Escrito, o folheto se oferece à leitura. Mas seu texto está repleto de marcadores que convidam à recitação pública: interpelação dos ouvintes, apóstrofes, exclamações admirativas ou indignadas estão em toda a narrativa. Obrigação estilística? Talvez. De fato e pelo menos no estado atual do seu uso, o folheto tem por vocação a leitura em voz alta, mesmo que solitária. (ZUMTHOR, 1980).

Para Câmara Cascudo, a noção que a academia sustenta acerca da história da literatura é formada no âmbito escolar, trazendo quase uma obrigatoriedade de que suas ideias tenham se originado nos centros, nos espaços urbanos, enquanto a literatura oral é quase "como se não existisse". Ele observa que, ainda que exista essa literatura oficial com seus diferentes estilos e nomenclaturas, que traz à tona o que conhecemos como "clássicos", existe uma literatura "sem nome" que sobrevive não somente das fontes (tendo parte considerável nos meios eruditos), mas de um movimento contínuo, suscitado pela imaginação, gerando sempre a sensação de que nós não fomos 
"iniciados" nas particularidades da literatura oral e continuamos a desconhecer essa "manifestação da cultura coletiva". (CASCUDO, 1984, p. 26-27).

As considerações feitas por Câmara Cascudo nos permitem inferir que a literatura de cordel também operou como instrumento de resistência, em primeiro plano para o poeta popular, que tem em sua produção uma maneira de posicionar-se diante do mundo, mas também para seu público, que por um longo período encontrava-se à margem do oficial, do erudito e também de uma voz com alcance, visto que, nos meios oficiais, só a voz dos dominadores poderia ser ouvida.

Tendo isso em vista, é preciso considerar que a literatura de cordel, em seu pioneirismo, possibilitou não somente a alfabetização de parte considerável de seu público (só este fato já seria suficiente para considerá-la um ícone de resistência), mas também gerou um processo de identificação e representação de seus ideais e visões de mundo, expressados nas folhas rusticamente impressas por Leandro Gomes de Barros, no início do século XX, e também na voz dos cantadores que frequentavam as praças e fazendas. De qualquer modo, é um equívoco concebermos a literatura de cordel como uma produção apreciada e consumida apenas por analfabetos ou iletrados, não somente pelo fato de o público ser mais amplo e diversificado na contemporaneidade, mas também pela atenção especial que lhe é dedicada por parte de figuras bastante reconhecidas.

Talvez a maior procura pelos folhetos de cordel não se justifique somente pelo fato de o público semiletrado ou analfabeto não compreender os escritos pertencentes à cultura erudita, mas também pelo processo de representação e identificação, tendo em vista que o ato de ouvir ou ler um folheto é muito menos dispendioso, financeiramente e socialmente, que frequentar uma livraria e ter acesso a diferentes formas de produção.

A literatura de cordel então, se apresenta de maneira livre e solta de diversas amarras porque não se deixa levar por imposições, já que quando estreitamos nosso contato com essa produção, encontramos poetas populares pioneiros trabalhando com de temáticas bastante heterogêneas, que também passeiam pela reescritura de obras eruditas de matriz europeia, o que nos possibilita compreender os diferentes papéis desempenhados pela literatura de cordel, em sua mais rudimentar produção, tanto no passado quanto na contemporaneidade. É sabido que para falar sobre a produção cordelista na contemporaneidade, antes de qualquer coisa, é preciso observar de que maneira essa literatura se firmou, como se constituíam os meios técnicos ou mecânicos de produção, de divulgação, bem como o perfil do público nordestino no início do século XX.

O cordel pioneiro contou com muitos folhetos que serviam como cartilhas veiculadoras de modelos de conduta para a comunidade, folhetos-romance (narrativas em versos com a presença de elementos mágicos), "folhetos de circunstância" (de caráter jornalístico/informativo), além de diversas críticas (a maioria satíricos) aos poderosos e detentores de terra e dos meios de produção no período elencado.

Esses elementos podem ser facilmente observados na rica produção do poeta paraibano Leandro Gomes de Barros (1865 - 1918), um dos principais nomes do cordel brasileiro, tendo sua obra reconhecida e admirada ainda hoje pelo público e também pelos pesquisadores de cultura popular, que continuam ávidos por compreender a difusão de seus folhetos, a manutenção de seu público, bem como a importância social que sua produção cordelista adquiriu ao longo de mais de cem anos.

Cabe ressaltar que as primeiras produções cordelistas aparecem entre o fim do regime monárquico e a Primeira República. Tais escritos desempenhavam, nas regiões em que eram divulgados, um papel de integração e socialização, visto que a escolaridade formal era quase inexistente no Nordeste de começo do século XX, de 
modo que os poetas e cantadores que frequentavam as praças e fazendas eram também agentes propagadores de notícias e de conscientização política e social. Nenhum local seria mais favorável para o esclarecimento do público que as praças e feiras, pela acessibilidade e democratização oferecida.

Os folhetos de cordel produzidos no Brasil são corriqueiramente associados à literatura de cordel ibérica, contudo, eles constituem formas de produção distintas, tendo o cordel brasileiro utilizado basicamente o nome e a opção pelas sextilhas como elementos mais caracterizadores, ainda que algumas temáticas também retomem as produções ibéricas de origem popular e erudita. Vale ressaltar que, ainda hoje, nas feiras e praças públicas, observamos que os folhetos não costumam ser expostos em cordas e barbantes, e sim lado a lado, geralmente no chão ou em espaços expositores que se assemelham a painéis.

Para ilustrar essa discussão, poderíamos pensar no fato de que Leandro Gomes de Barros, por exemplo, foi um poeta popular completo, o que impulsionou seu contato com textos de toda ordem, tendo inclusive escrito alguns sonetos (uma forma não popular) feito esse repetido mais tarde por Rodolfo Coelho Cavalcante.

Além disso, o diálogo com a cultura erudita se estabelece também na releitura e na reescritura de famosos textos literários como Amor de Perdição, de Camilo Castelo Branco, A escrava Isaura, de Bernardo Guimarães e tantos outros, tendo o professor Stélio Torquato Lima até lançado uma coleção de folhetos baseada em clássicos da literatura.

Até por isso, não raramente nos deparamos com formas utilizadas por poetas populares da Primeira República que muito se assemelham às utilizadas nos folhetins que circulavam na então capital federal, Rio de Janeiro, além é claro, dos poetas estarem sempre muitíssimo bem informados a respeito do que ocorria no Brasil e no mundo, é o que podemos apreender do fragmento de O povo na cruz (1907/1908), no qual o poeta traz duras críticas ao recém constituído regime republicano:

O brasileiro hoje em dia

Luta até para morrer

Porque depois dele morto

Tudo nele quer roer,

De forma que até a terra

Não acha mais o que comer.

A fome come-lhe a carne

O trabalho gasta o braço

Depois o governo pega-o

Há de partir o compasso

Alfandega, Estado e Intendência

Cada um tira um pedaço.

O médico cobra a receita

O boticário a meizinha

O juiz confisca logo

Alguns bens se acaso tinha

Inda ficando uma parte

Diz a Intendência, é minha.

Assim morre o brasileiro

Como o bode é exposto a chuva

Tem por direito o imposto 
E palmatória por luva

Família só herda dele

Nome de órfão e viúva.

Morrendo um pobre diabo

Se acaso deixar dinheiro

Ainda deixando um filho

Este não é seu herdeiro

Só herde dele o juiz

O escrivão e o coveiro. [...] (BARROS, 1907/1908, p. 1-2).

No entanto, esse fenômeno não é exclusivo à produção dos poetas pioneiros, mas aparece nos folhetos de Gonçalo Ferreira da Silva, por exemplo, poeta cearense radicado no Rio de Janeiro. Gonçalo faz menção a famosos cientistas e personalidades históricas e literárias, como ocorre em seu folheto Adeus Drummond, no qual pela ocasião da morte do poeta mineiro, ele resolve homenageá-lo:

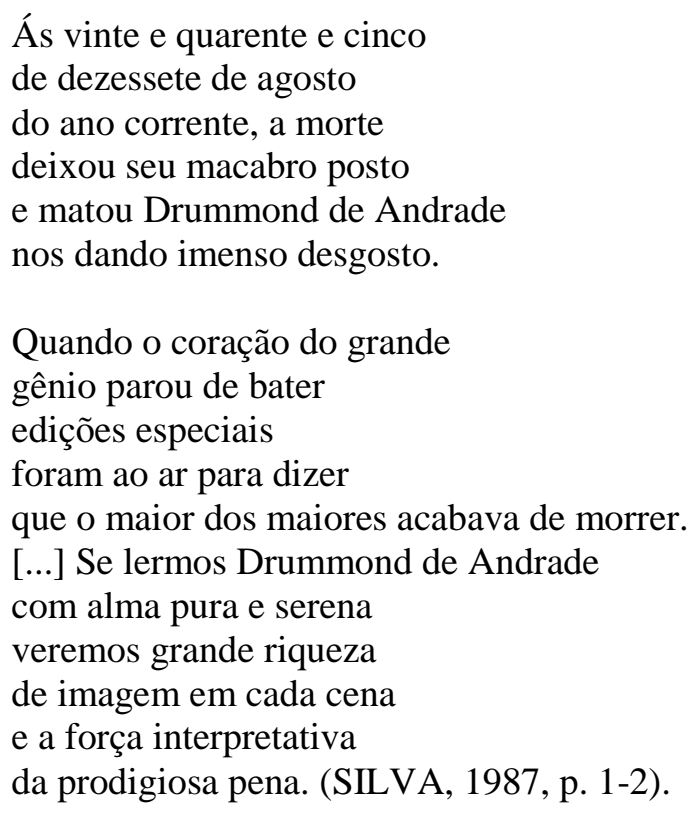

A noção de reciprocidade poderia se dar já neste âmbito, porque os poetas populares desde sempre leram poetas e escritores chamados "eruditos", antes por meio do jornal, companheiro fiel do cordel brasileiro e depois também no formato livro.

Desta forma, não podemos deixar de mencionar a recriação da notícia feita por Gonçalo Ferreira da Silva, por exemplo, que rompe com a estrutura midiática do jornal ou revista e dá voz a seu público, tratando os assuntos de maneira mais pessoal e humanizada, com um olhar que se difere do retratado nos meios de comunicação de massa, como em Meninos de rua e a chacina da candelária:

\footnotetext{
No Brasil entorpecido

pelo odor infernal

que exala do plenário

do Congresso Nacional

o fato mais deprimente

é tido como normal.
}

[...]São grupos de extermínio 


\author{
formados nas regiões \\ por soldados dissidentes \\ de muitas corporações \\ mantidos pelo comércio \\ para assassinar ladrões. \\ Com o aparecimento \\ dessas turmas sanguinárias \\ as chacinas se tornaram \\ praticamente diárias \\ e sete ou oito por dia \\ as execuções sumárias. \\ É com sadismo cruel, \\ praticada a chacina \\ sem tempo para pedir \\ comiseração divina \\ sem defesa, sem clemência \\ é feita a carnificina.
}

São as crianças de rua ou os bandidos frustrados, os delinquentes comuns, ao vício subjugados que rasgam a noite sem teto e despertam assassinados.

Há motivos para esses assassinatos em massa. A imprensa se limita em dizer o que se passa porém não fala da causa que provocou essa desgraça. (SILVA, s. d., p. 3-4).

É preciso salientar que, ao contrário do poeta popular contemporâneo, frequentador da academia, com uma produção mais elaborada, capaz de dialogar com a cultura erudita e a de massa, o cordelista pioneiro utilizava a literatura de cordel como forma de expressão de sua visão de mundo e a de seus pares, geralmente com pouquíssima instrução e quase nenhuma escolaridade formal, adquirindo hábitos de leitura e escrita com base na leitura de jornais da época e transformando a literatura de cordel do período em um "jornal popular".

Ainda que seja verdadeiro o fato de que o trabalho formal dos folhetos pioneiros não era tão presente, essencialmente na forma, já que é possível observar muitas repetições de palavras, vale ressaltar que algumas delas possuíam, inclusive, papel ideológico, como nos folhetos sobre a emancipação feminina, nos quais Leandro Gomes de Barros utiliza à exaustão a expressão "meretriz" para se referir às mulheres que aderiram à moda da época e aos novos hábitos daquela sociedade que se formava, deixando de ser essencialmente rural para ganhar ares citadinos.

A literatura de cordel produzida na Primeira República apresentava temáticas muito localistas, esquemas e clichês que ainda se repetem, embora com menor intensidade. É importante sinalizar que, embora o cordel pioneiro tenha sido reconhecido e bem assimilado por um considerável público leitor/ouvinte (no ato 
individual da leitura do folheto ou no coletivo recebendo-o por meio do cantador nas praças públicas), servia a determinado segmento social e não suscitava a curiosidade e o interesse de um público mais urbano e diversificado.

Com isso, o cordel brasileiro atravessou uma fase de declínio na década de 1960, o que não significa, em nenhuma circunstância, que a produção cessou (porque isso nunca ocorreu), mas sim que a literatura de cordel sofreu uma queda, contando com poucos poetas populares reconhecidos e correndo o risco de cair no esquecimento. Esse declínio, não à toa, caminhou lado a lado com a popularização dos novos meios de comunicação, além de outras formas de entretenimento muito antigas como a fotonovela, a radionovela e posteriormente, a telenovela.

O público leitor/ouvinte era atraído também pelo divertimento proporcionado pelo cordel, além de se sentir representado pela voz do poeta popular. No Brasil, com a popularização das novelas, a literatura de cordel acabou perdendo espaço e a cultura de massa foi ganhando um público mais amplo e diversificado, haja vista que oferecia entretenimento rápido, simples e de fácil acesso.

Os meios de comunicação de massa, então, representaram uma ameaça à sobrevivência da poesia de cordel e aos próprios poetas populares, que decidiram atrair um novo público e também ampliar o público cativo, por meio de modificações de ordem técnica, melhorando o trabalho com a linguagem, adotando novas temáticas e inclusive utilizando novos veículos de divulgação, como a internet, por exemplo.

A "ameaça" dos meios de comunicação de massa não era motivo de preocupação somente por prejudicar o orçamento dos poetas populares, mas também por colocar em xeque o relacionamento destes com a própria tradição, com sua necessidade de representação, sem contar a sua própria representatividade junto a seu público.

A literatura de cordel como elemento utilizado na intenção de obter principalmente sustento do poeta e de sua família é um fenômeno mais recente, digamos que mais conhecido a partir de poetas como Rodolfo Coelho Cavalcante, que sempre se preocupou com a profissionalização e o reconhecimento do poeta popular, reivindicando espaço tal qual o ocupado pelos escritores "eruditos".

Para esta discussão utilizamos o conceito de Indústria Cultural, desenvolvido por Adorno e Horkheimer, também chamado de "cultura de massa" por outros teóricos, como um dos recursos que ajudaram a constituir o novo cordel brasileiro, sempre tendo em vista que hoje há interpretações diferentes acerca da cultura de massa, que não permitem que ainda analisemos essas relações com a mesma régua utilizada por Adorno, porque se hoje discutimos as noções de cultura e o trânsito entre elas, parece bastante pertinente refletir acerca dos "modos de fazer e usar socialmente a arte", como observa Jesús Martín-Barbero:

Sabemos que a crítica ao prazer tem razões não só estéticas. Os populismos, fascistas ou não, têm predicado sempre as excelências do realismo e têm exigido dos artistas obras que transpareçam os significados e que se conectem diretamente com a sensibilidade popular. Mas a crítica de Adorno, falando disso, aponta, contudo, para outro lado. Cheira demais a um aristocratismo cultural que se nega a aceitar a existência de uma pluralidade de experiências estéticas, uma pluralidade dos modos de fazer e usar socialmente a arte. Estamos diante de uma teoria da cultura que não só faz da arte seu único verdadeiro paradigma, mas também que o identifica com seu conceito: um "conceito unitário" que relega a simples e alienante diversão qualquer tipo de prática ou uso da arte que não possa ser derivado 
daquele conceito, e que acaba fazendo da arte o único lugar de acesso à verdade da sociedade. (BARBERO, 2009, p. 78).

As discussões que rondam em torno das noções de cultura permanecem atuais e coerentes com a necessidade de explicar não somente o processo de difusão dos elementos pertencentes às culturas populares, mas também de que forma a recepção se consolida a cada dia, ainda que tenhamos consciência do estreitamento desta mesma recepção causado pela Indústria Cultural.

Ao pensar na pluralidade de experiências estéticas mencionada por Barbero no fragmento acima, também conseguimos adequar essa consideração ao contexto do cordel brasileiro. Se a literatura de cordel conserva a tradição e ainda desperta nossa curiosidade por seus personagens maravilhosos, pelas pelejas, pelas discussões, pelas histórias de Lampião e de seu bando, pelos heróis que fogem nas asas do pavão misterioso, ela também se mistura a outras tendências para continuar buscando seu referencial mais antigo: a identidade.

Os indivíduos que liam ou ouviam os folhetos dos cordelistas de fôlego da era republicana, buscavam informação, entretenimento, e é claro, identificação. Esses intentos e preocupações permanecem envolvendo a produção cordelista contemporânea, o que nos leva a crer que o cordel se modifica na medida em que precisa alcançar um novo público e manter-se vivo, dinâmico, sem, contudo, esquecer as preocupações de ordem financeira do poeta e seus anseios de projetar a sua própria voz e também de oferecer a seus pares um espaço, agindo como porta-voz de um grupo.

\section{Considerações finais}

Neste artigo procuramos esboçar, embora brevemente, comentários sobre reciprocidade ou circularidade entre culturas, bem como apresentarmos alguns dos motivos que fizeram com que a literatura de cordel quase em total declínio na década de 60do século passado.

O fenômeno da circularidade entre culturas remonta os tempos mais remotos. No Nordeste brasileiro, poetas como Leandro Gomes de Barros, Francisco das Chagas Batista e João Martins de Athayde escreveram muitos de seus famosos "romances" a partir de narrativas populares e eruditas medievais, trazidas ou pelos colonizadores europeus ou aqui aportadas de meados do século XIX em diante.

O que nos chama atenção, de fato, é a capacidade do cordel brasileiro de utilizar seus próprios "concorrentes" contemporâneos, no caso, as opções oferecidas pelos meios de comunicação de massa e pela Indústria Cultural, para então fazer uma reafirmação ou talvez revitalização de suas técnicas e temáticas.

$\mathrm{Na}$ contemporaneidade, a literatura de cordel conquistou novos espaços praças, feiras, exposições, bancas de revistas etc. - que já não cabe mais no rótulo de literatura regionalista, consumida por um público pouco alfabetizado, preconceitos que pouco ajudaram, de fato, a definir o cordel.

Ainda assim, não devemos esquecer que a tradição continua sendo importantíssima para essa forma de produção, do contrário, a estrutura, a oralidade, o ritmo e até mesmo alguns recursos, como a reescritura de folhetos famosos, deixariam de ser elementos caracterizadores do cordel, permitindo que caísse no esquecimento.

Até entre os novos cordelistas e o novo público do cordel há preocupação em não atribuir esse título a toda e qualquer produção que se assemelhe a ele, mas também parece necessário que finalmente pensemos na liberdade conquistada por essa produção 
que se soltou das amarras que lhe foram impostas por tanto tempo. Este aspecto é comentado por Maria Alice Amorim em Literatura de Cordel: tradição e contemporaneidade:

E se a gente considera que cultura é um organismo vivo, dinâmico, o cordel não estaria se saindo muito bem nesse processo adaptativo? $\mathrm{E}$ se a gente, invés de alardear que "a forma inculta" do cordel morreu, que o que temos agora é um cordel artificial, fosse pesquisar a produção cordelista dos atuais poetas de gabinete - quer sejam universitários, pós-graduados, secundaristas, não escolarizados - para, de fato, conferir o legado poético contemporâneo e ouvir os próprios autores acerca da relação afetiva, social, história, familiar que trazem inscrita nas respectivas biografias quanto às influências dos clássicos do cordel? Não seria bom, invés de aplainar esse terreno, estudar melhor os detalhes da topografia, do relevo, das paisagens tão ricas em nuances, em complexas misturas das pós-modernidade? (AMORIM, 2010, p. 170).

O cordel continua muito rico e realmente vivo por ter se reafirmado e conseguido vencer esse processo adaptativo mencionado no fragmento acima. Poetas como Gonçalo Ferreira da Silva, inserido no contexto carioca, continua produzindo folhetos que agradam a todos aqueles transeuntes, que, curiosos, passam pela Feira de São Cristóvão e na loja da ABLC (Academia Brasileira de Literatura de Cordel), no bairro de Santa Teresa, e param para ouvir, ler ou discutir sobre os títulos ali expostos. Mas os folhetos agradam também a acadêmicos e pesquisadores, que agora desarmados, começam a estudá-los para entender melhor o lugar ocupado por essa literatura no âmbito da cultura popular brasileira.

\section{Referências}

AMORIM, Maria Alice. Literatura de cordel: tradição e contemporaneidade. Recife: Folha de Pernambuco, 2010.

BARBERO, Martin-Jesús. Dos meios às mediações: comunicação, cultura, hegemonia. Trad. Ronald Polito e Sérgio Alcides. Rio de Janeiro: UFRJ, 2009.

CAÇÃO, Barbara Lais Falcão da Silva. Tempos de Barbante: declínio e revitalização da literatura de cordel. Da Primeira República à contemporaneidade. 115 f. Dissertação (Mestrado em Letras) - Faculdade de Ciências e Letras, Universidade Estadual Paulista, Assis, 2016.

CANDIDO, Antonio. O direito à literatura. In: Vários Escritos. Rio de Janeiro: Ouro sobre azul, 1988.

CASCUDO, Luís da Câmara. Literatura Oral no Brasil. Belo Horizonte: Itatiaia; São Paulo: Edusp, 1984.

GINZBURG, Carlo. O queijo e os vermes: o cotidiano e as ideias de um moleiro perseguido pela Inquisição. São Paulo: Companhia das Letras, 2006. 
LUYTEN, Joseph Maria. O que é literatura popular. São Paulo: Brasiliense, 1987.

MARQUES, Francisco Cláudio A. Um pau com formigas ou o mundo às avessas: a sátira na poesia popular de Leandro Gomes de Barros. São Paulo: Edusp/Fapesp, 2014.

PROENÇA, Ivan Cavalcante. A ideologia do cordel. 3. ed. Rio de Janeiro: Plurarte, 1982.

SILVA, Gonçalo Ferreira. Adeus, Drummond. Rio de Janeiro: ABLC, 1987. Disponível em: http://docvirt.com/docreader.net/CordelFCRB2/43414. Acesso em 07 de janeiro de 2017.

SILVA, Gonçalo Ferreira. Meninos de rua e a chacina da candelária. Rio de Janeiro: ABLC, s.d. Disponível em: http://docvirt.com/docreader.net/CordelFCRB2/45085. Acesso em 07 de janeiro de 2017.

ZUMTHOR, Paul. A escrita e a voz (de uma literatura popular brasileira). Trad. Idelette Muzart, in Plural Pluriel Revue des culture de langue portugaise. Acesso em 24 de outubro de 2016: http://revue1-13.pluralpluriel.org/

Recebido em: outubro de 2016.

Aprovado em: dezembro de 2016. 